\title{
Estudo de baixa visibilidade no aeroporto de Porto Alegre: simulação numérica com o modelo PAFOG
}

A elaboração deste trabalho foi motivada pela carência de um método eficaz de previsão de visibilidade no aeroporto Salgado Filho (Porto Alegre, RS). Os objetivos principais são: 1) simular, usando o modelo PAFOG, os eventos de visibilidade baixa causados por nevoeiros de radiação no aeroporto de Porto Alegre nos anos 2008 e 2009 e 2) avaliar os resultados das simulações inicializadas com diferentes fontes de dados. Perfis verticais de radiossondagem e de dados de previsão (CFSR-2) do modelo CFSR foram utilizados para as inicializações do modelo. Nas inicializações foram utilizados dados de superfície com as duas fontes. Variáveis na camada limite (CL) foram calculadas com dados do modelo CFSR (análise CFSR-1 e CFSR-2). Os dados de altitude foram obtidos de radiossonda e CFSR-2 (resolução $0,5^{\circ}$ ). Foram selecionados todos (13) casos de nevoeiros de radiação nas horas de observação de radiossondagem. Foram analisadas as condições físicas da baixa troposfera: 1) analise sinótica e de meso escala com produtos de reanálise do NCEP e CFSR-1 com 2, $5^{\circ}$ e satélite GOES-12; 2) dinâmica acima da CL com CFSR-1 e CFSR-2 com $0,5^{\circ}$, e 3) perfil vertical de umidade relativa (UR) com radiossondagem e produtos do CFSR-2 com $0,5^{\circ}$. Foram feitas 25 inicializações com perfis de radiossondagem e 48 com perfis do CFRS-2 com antecedência de até $22 \mathrm{~h}$. Nos horários das inicializações as análises sinótica, dinâmica e de perfil de UR mostraram condições favoráveis ao uso do PAFOG. Em algumas situações foram detectados erros da extrapolação do ponto de orvalho com os perfis do CFSR-2. A influência das extremidades de Sistemas Frontais (SF) em algumas inicializações gerou vento geostrófico superior ao limite suportado pelo modelo PAFOG. Com perfis do CFSR-2 o PAFOG acertou visibilidade de nevoeiro em 36 simulações e não acertou em 12 (em 10 devido aos erros na extrapolação de UR e em 2 devido a influência de SF). Com O CFSR-2 as melhores simulações foram inicializadas às 1200 UTC do dia anterior ao evento e às 0000 UTC do dia do evento. Com perfis de radiossonda o PAFOG acertou visibilidade de nevoeiro em 22 simulações e não em 3 . Os resultados mostraram um grande potencial do uso do PAFOG para a previsão de nevoeiros no aeroporto Salgado Filho, porém, também mostraram necessidade para adaptar o modelo às condições climáticas da região.

Palavras-chave: Visibilidade; Nevoeiro de Radiação; Modelo PAFOG.

\section{Low visibility study at Porto Alegre airport: numerical simulation with PAFOG model}

\begin{abstract}
Elaboration of this work was motivated by the lack of an effective visibility forecasting method for the Salgado Filho airport (Porto Alegre, RS). The main purposes are: 1) to simulate low visibility events caused by radiation fog at the Porto Alegre airport, using the PAFOG model and 2) evaluate the results of simulations started with different data sources. Vertical Profiles by radiosonde and forecasted using the data (CFSR-2) of the CFSR model were used for model initializations. Two sources of the surface data were used for initializations. Boundary layer (BL) radiosonde and forecasted using the data (CFSR-2) of the CFSR model were used for model initializations. Two sources of the surface data were used for initializations. Boundary layer (BL)
variables were calculated with CFSR model data (reanalysis CFSR-1 and CFSR-2). Altitude data were obtained from radiosonde and CFSR-2 data (0.5 resolution). All (13) events of radiation variables were calculated with CFSR model data (reanalysis CFSR- 1 and CFSR-2). Altitude data were obtained from radiosonde and CFSR-2 data $\left(0.5^{\circ}\right.$ resolution). All (13) events of radiation
fog were selected at the hours of radiosonde observations. The next physical conditions of the lower troposphere were analyzed: 1 ) synoptic and mesoscale analysis of NCEP and CFSR-1 (2.5 resolution) reanalysis products and GOES-12 satellite; 2 ) dynamic above the BL with CFSR-1 and CFSR-2 (0.5 resolution) and 3 ) vertical profile of the relative humidity (RH) from radiosonde and $0.5^{\circ}$ CFSR- 2 products. It was elaborated 25 initializations with radiosonde profiles and 48 with CFRS- 2 profiles with antecedence up to $22 \mathrm{~h}$. Synoptic, dynamic and RH profile analyzes during the initialization showed favorable conditions for the use of the PAFOG model. Dew point extrapolation errors from CFSR-2 profiles were detected in some situations. An influence of the Frontal Systems (SF) extremities in some initializations generated geostrophic wind above the limit supported by the PAFOG model. PAFOG using CFSR-2 profiles simulated fog-like visibility in 36 initializations and did not simulate in 12 (10 due to errors in the relative humidity extrapolation and 2 due to SF influence). The best simulations of PAFOG with CFSR were started at 1200UTC at the day before the event and at 0000UTC at the event day. PAFOG with radiosonde profiles simulated fog-like visibility in 22 initializations and did not predict in 3 . Results showed a great potential for the use of the PAFOG model for a fog forecasting at Salgado Filho airport, but also showed the necessity to adapt the model with the regional climatic condition.
\end{abstract}

Keywords: Visibility; Radiation Fog; PAFOG Model.

Topic: Meteorologia, Climatologia e Mudanças Climáticas

Reviewed anonymously in the process of blind peer.
Received: 02/10/2019

Approved: 26/11/2019
João Maria de Sousa Afonso ii

Instituto Nacional de Pesquisas Espaciais, Brasil

http://lattes.cnpq.br/4114434960992264

http://orcid.org/0000-0002-9506-4642

joaoafonso19@gmail.com

Natalia Fedorova (iD)

Universidade Federal de Alagoas, Brasil

http://lattes.cnpq.br/6240947588482690

http://orcid.org/0000-0002-4154-6830

nataliabras@gmail.com

Vladimir Levit

Universidade Federal de Alagoas

http://lattes.cnpq.br/1231943260451104

vladimirle@gmail.com
Lianet Hernández Pardo (iD

Instituto Nacional de Pesquisas Espaciais, Brasil

http://lattes.cnpq.br/5221080141445775

http://orcid.org/0000-0002-5653-9705

Ihpardo90@gmail.com
Referencing this:

AFONSO, J. M. S.; FEDOROVA, N.; LEVIT, V.; PARDO, L. H.. Estudo de baixa visibilidade no aeroporto de Porto Alegre: simulação numérica com o modelo PAFOG. Revista Ibero Americana de Ciências Ambientais, v.10, n.6, p.114-130, 2019. DOI:

http://doi.org/10.6008/CBPC2179-6858.2019.006.0011 


\section{INTRODUÇÃO}

Um modelo de previsão de visibilidade baixa associada a nevoeiros (PArametrized FOG - PAFOG) foi desenvolvido na Alemanha por Bott et al. (2002) especificamente para nevoeiro de radiação e nuvens estratiformes de baixos níveis. Esse modelo vem sendo testado em eventos de nevoeiros intensos, nos últimos anos, na região nordeste do Brasil (NEB) com inicializações de produtos de modelos regionais de alta resolução MM5 e WRF (FEDOROVA et al., 2013; FEDOROVA et al.; 2015). Também foi testado o efeito da vegetação da região NEB na simulação de nevoeiro do modelo (FEDOROVA et al.; 2015). Nesses trabalhos, a formação de nevoeiro foi simulada pelo modelo PAFOG e foram obtidos resultados satisfatórios com 10h de antecedência. Foi constatado nesses estudos que não ouve efeito significativo das condições de vegetação (rápido crescimento da cana de açúcar) sobre a visibilidade simulada pelo PAFOG. No entanto, foi observada uma tendência a simulações mais precisas da visibilidade, da duração e do início do nevoeiro com o uso da parametrização de armazenamento de água máxima da folhagem.

No mundo científico, convênios são muito importantes para o desenvolvimento de pesquisas bilaterais em diversas esferas da sociedade. Com o mesmo intuito, foi feito um convênio internacional entre o Instituto de Ciências Atmosféricas (ICAT) da Universidade Federal de Alagoas (UFAL), Brasil, e a Faculdade de Matemática e Ciências Naturais da Universidade de Bonn, Alemanha, que possibilitou a obtenção do modelo PAFOG. Essa parceria tem sido de mais valia pois o PAFOG vem sendo testado pelo Laboratório de Meteorologia Sinótica e Física do ICAT/UFAL para a previsão de nevoeiros em diversos aeroportos do Nordeste do Brasil (FEDOROVA et al., 2013; FEDOROVA et al.; 2015).

Pelo conhecimento dos autores, não existem estudos com métodos numéricos de previsão de visibilidade associados a nevoeiros em Porto Alegre e o modelo PAFOG não foi testado em outras regiões do Brasil, exceto a região NEB. Por isso, nesta pesquisa o objetivo principal é de simular os eventos de visibilidade baixa causados por nevoeiros de radiação no aeroporto Salgado Filho, Porto Alegre, e avaliar os resultados das simulações inicializadas com perfis de diferentes fontes de dados necessários para a inicialização do modelo PAFOG. A seleção, classificação e análise detalhada dos nevoeiros de radiação usados para a simulação neste trabalho foram apresentadas na primeira parte do estudo.

Em seguida, é apresentada uma breve descrição do modelo de previsão de visibilidade (PAFOG), as fontes de dados utilizados para as inicializações das simulações, bem como a descrição dos métodos usados para caracterizar as condições físicas da baixa troposfera nos horários das inicializações. Na seção dos resultados se apresenta uma descrição dos resultados dos testes do modelo PAFOG, também são relatados os problemas encontrados nas inicializações que influenciaram na falha das simulações em acertar os nevoeiros. As principais conclusões são resumidas na seção 'Conclusões'.

\section{METODOLOGIA}

\section{Região de estudo e seleção dos casos de nevoeiros}

O presente estudo está baseado nos resultados obtidos na primeira parte do estudo, onde foram 
analisados os processos sinóticos e termodinâmicos que influenciaram a formação dos nevoeiros ocorridos no aeroporto Salgado Filho ( $30^{\circ} 00^{\prime} \mathrm{S}, 51^{\circ} 18^{\prime} \mathrm{W}$ a $3 \mathrm{~m}$ de altitude) localizado na cidade de Porto Alegre, estado do Rio Grande do Sul, durante os anos de 2008 e 2009. Os casos selecionados para as simulações com o modelo PAFOG foram os 13 eventos de nevoeiros de radiação (apresentaram visibilidade horizontal inferior a $1000 \mathrm{~m}$ ) (TUBELIS-NASCIMENTO, 1983).

\section{Simulação de visibilidade usando o modelo PAFOG}

O PAFOG (Parametrized FOG) é um modelo unidimensional para previsão de visibilidade dos nevoeiros ocorridos dentro de uma massa de ar e de nuvens estratiformes de baixos níveis. Ele está composto por 4 módulos: dinâmico, microfísica, radiação e vegetação baixa (BOTT et al., 2002). Para simulação de visibilidade no nevoeiro (da superfície até um nível z1), a coluna atmosférica é subdividida em N1 camadas da mesma espessura. Os valores de z1 e N1 são, por padrão, configurados para 400 m e 50, respectivamente, mas seus valores podem ser alterados, de acordo com as necessidades do usuário. Um segundo modo de simulação, que se estende do nível z1 até o nível z2 é subdividido logaritmicamente em N2 camadas equidistantes (simulação de visibilidade em nuvens estratiformes).

Os valores de z2 e N2 foram configurados neste estudo para 1500 m e 20, respectivamente. Os processos de microfísica de nuvens são calculados somente nas regiões equidistantes do modelo. Para uma determinada simulação, o topo do nevoeiro ou stratus (camada úmida) no perfil inicializado não deve exceder a altura z1; se positivo os cálculos do modelo são automaticamente interrompidos. A parte dinâmica do PAFOG consiste em um conjunto de equações prognósticas para o campo de vento horizontal, temperatura potencial e umidade específica (BOTT et al., 1990; SIEBERT et al., 1992). A turbulência é tratada com o 2,5 level model of Mellor et al. (1982). Cálculos de radiação são realizados com o $\delta$-two stream approximation of Zdundowski et al. (1982).

\section{Dados de entrada do PAFOG}

Os dados de entrada do modelo PAFOG estão divididos em 4 partes: PARTE 1: dados geográficos (latitude, longitude $\left({ }^{\circ}\right)$ e altitude $(\mathrm{m})$ da região de estudo); tipo e textura do solo; altura $(\mathrm{m})$ e cobertura da vegetação; dados meteorológicos da estação (pressão em hPa; as temperaturas do ar, ponto de orvalho na superfície, temperatura do ar em $2 \mathrm{~m}$ e temperatura do solo, todas em ${ }^{\circ} \mathrm{C}$; visibilidade em $\mathrm{m}$. PARTE 2 : nebulosidade em baixos, médios e níveis elevados em okta e tipo de aerossol. PARTE 3: dados de radiossondagem (pressão em $\mathrm{hPa}$; altura geopotencial em $\mathrm{m}$, as temperaturas do ar e ponto de orvalho em ${ }^{\circ} \mathrm{C}$ ) e dados de velocidades vertical e do vento geostrófico acima da camada limite $(\mathrm{CL})$ em m/s. PARTE 4: temperatura $\left({ }^{\circ} \mathrm{C}\right)$ e umidade $(\%)$ do solo em diferentes profundidades; altura $(\mathrm{m})$ do ponto mais alto observado ao redor da região e nível da altura que os nevoeiros e os stratus atingem sobre a região. Fedorova et al. (2015) utilizaram o PAFOG na região Nordeste do Brasil com algumas variáveis inalteradas no modelo. Diferente do estudo anterior, nesta pesquisa foram incluídos os dados de tipo de aerossol de acordo com Bott et al. (2002) na PARTE 2. 
Na PARTE 3 o PAFOG foi inicializado com perfil vertical observados de radiossonda do aeroporto Salgado Filho, obtidos no Departamento of Atmospheric Sciences/University of Wyoming ${ }^{1}$ e com o produto de previsão (CFSR-2) do modelo Climate Forecast System Reanalysis (CFSR)². Embora os produtos de reanalises em geral, destacando o do modelo CFSR (CFSR-1), usam assimilação de dados observados para a melhoria dos produtos (KALNAY et al., 1996), o mesmo não dispõe de dados na superfície, por isso se optou o uso do CFSR-2 que dispõe dessas informações necessárias para a inicialização do PAFOG e para a determinação da altura da camada limite $(\mathrm{CL})$ que foi usada como referência nas inicializações do PAFOG com as duas fontes de perfil vertical (radiossonda e CFSR-2).

Nas inicializações com perfis de radiossonda as informações específicas de velocidade vertical e do vento geostrófico acima da CL foram calculadas usando os dados do CFSR-1 com espaçamento de grade horizontal de $0,5^{\circ}$. Nas inicializações feitas com perfis do CFSR-2 os valores da velocidades vertical e do vento geostrófico foram calculados com a mesma fonte. Com isso, foi possível avaliar os resultados das simulações do PAFOG usando perfis verticais de diferentes fontes (radiossonda e CFSR-1).

Devido às limitações dos dados utilizados foi necessário realizar extrapolações para obter os valores correspondentes a determinados níveis. Nas simulações com perfis de radiossonda o valor da temperatura do ar em 2 m de altura foi obtido mediante a extrapolação do valor fornecido pela sondagem no nível de superfície. Nas simulações com perfis do CFSR o ponto de orvalho em superfície foi obtido a partir do valor desta variável a $2 \mathrm{~m}$ de altura.

As restantes informações necessárias para as inicializações das simulações foram mantidas as mesmas nas duas categorias apresentadas acima (inicializações com perfis de radiossonda e com CFSR-2) como pode ser visto a seguir: Na PARTE 4 a altura do ponto mais alto observado ao redor do aeroporto foi de $49 \mathrm{~m}$, obtidas de Smith et al. (1997); os níveis mais alto que os nevoeiros e os stratus atingem (de $400 \mathrm{~m}$ e $1500 \mathrm{~m}$, respectivamente) e a temperatura e umidade do solo em profundidade foram mantidas a padrão do modelo (BOTT et al., 2002).

Os dados horários da estação meteorológica de superfície do aeroporto Salgado Filho foram obtidos na Rede de Meteorologia do Comando da Aeronáutica - REDEMET ${ }^{3}$ e usados como dados de entrada para as PARTES 1, 2 e 4 . O tipo de solo configurado foi o argiloso (PIELKE, 1984). A vegetação foi mantida a de Bott et al. (2002) conforme os resultados de Fedorova et al. (2015). O PAFOG permite a configuração de 4 tipos de aerossóis (rural, urbano, marítimo e troposférico), neste trabalho usou-se o tipo de aerossol urbano porque o aeroporto está localizado na cidade de Porto Alegre.

O PAFOG foi usado para simular a visibilidade na formação dos nevoeiros com o alcance máximo de $24 \mathrm{~h}$ antecedência, com resolução temporal de $12 \mathrm{~h}$ para as inicializações com perfis de radiossonda (até 2 simulações por evento) e com resolução de $6 \mathrm{~h}$ com perfis do CFSR-2 (até 4 simulações por evento). A figura 1 representa de forma esquemática o diagrama de inicialização do modelo PAFOG.

\footnotetext{
${ }^{1}$ http://www.weather.uwyo.edu/

${ }^{2}$ http://rda.ucar.edu/pub/cfsr.htm

${ }^{3}$ https://www.redemet.aer.mil.br
} 
Finalmente, foi possível avaliar os resultados das simulações do PAFOG como: 1) as melhores sendo aquelas que acertaram os valores de visibilidade dos nevoeiros e não foram automaticamente interrompidas, com a intensidade e duração mais próximas das observadas e 2) o não acerto das simulações as que não acertaram os valores de visibilidade dos nevoeiros. Também foi possível chegar a uma conclusão sobre a possibilidade de utilização do PAFOG para a previsão de nevoeiro no aeroporto Salgado Filho.

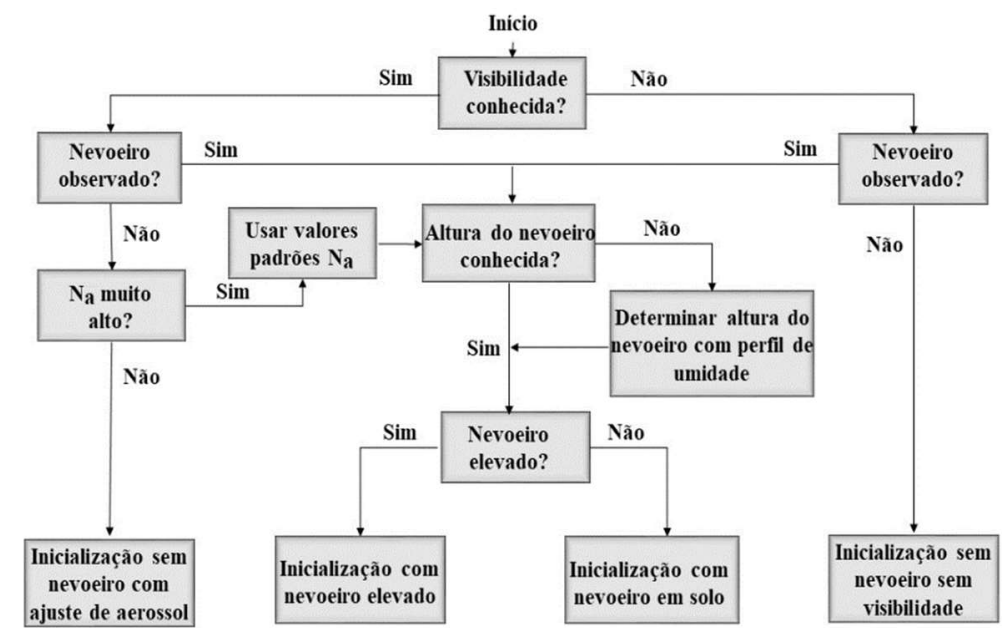

Figura 1: Diagrama de inicialização do modelo PAFOG para a previsão de visibilidade associadas a eventos de nevoeiros. $\mathrm{N}_{a}$ é o nível da camada úmida do perfil inicializado.

\section{Análise das condições da baixa troposfera nos horários das inicializações}

Foram analisadas as condições da baixa troposfera nos horários das inicializações do PAFOG, tais como: 1) processo sinótico e de meso escala na baixa troposfera, 2) perfil vertical de UR e 3) dinâmica acima da CL. Para 1) foram utilizadas imagens do Geostationary Operational Environmental Satellite (GOES) 12 no canal infravermelho da NOAA e campos das variáveis de Pressão a Nível Médio do Mar (PNM) e Linhas de escoamento e isotacas nos níveis de $1000 \mathrm{hPa}, 925 \mathrm{hPa}$ e $850 \mathrm{hPa}$ no domínio entre $25^{\circ}$ e $35^{\circ} \mathrm{S}$ e entre $44^{\circ} \mathrm{e}$ $58^{\circ} \mathrm{W}$. Esses campos foram gerados com os produtos de reanálise do National Centers of Environmental Prediction/National Oceanic and Atmospheric Administration (NCEP/NOAA) ${ }^{5}$ e do CFSR-1, ambos com espaçamento de grade horizontal de $2,5^{\circ}$. Assim foi possível determinar os sistemas sinóticos e de meso escala que predominavam sobre a região nos horários das inicializações, e também, comparar a representação dos dois produtos (NCEP e CFSR-1). Na primeira parte do estudo foi descrito detalhadamente quais e como são identificados os sistemas de escala meso e sinótica que atuam sobre a região de estudo. Para a análise de perfil vertical de umidade foram usados os dados de radiossonda do aeroporto e do CFSR2. A análise dinâmica acima da camada limite foi feita com os dados do CFSR-1 e CFSR-2 como descrito na secção 2.2.1.

\footnotetext{
${ }^{4}$ http://www.ncdc.noaa.gov/gibb

${ }^{5}$ http://www.cdc.noaa.gov
} 


\section{RESULTADOS}

\section{Simulação de visibilidade com o PAFOG nos nevoeiros de radiação}

Nas secções seguintes apresenta-se detalhadamente as condições da baixa troposfera nos horários das inicializações para a simulação de baixa visibilidade associadas aos 13 eventos de nevoeiros de radiação, bem como os resultados simulados pelo modelo PAFOG. Os nevoeiros de radiação normalmente se formam nos anticiclones velhos que se tornam termicamente estáveis (WILLET, 1928). Essa característica favorece a utilização do PAFOG levando em conta o máximo período de integração do modelo (24 horas). Entretanto, as inicializações normalmente são feitas em condições de atmosfera seca ou de camada úmida rasa devido à subsidência.

No geral, foram feitas 25 inicializações com os dados de sondagem observada, variando entre $22 \mathrm{~h}$ e $3 \mathrm{~h}$ de antecedência aos eventos de nevoeiro. Com o CFSR-2 foram feitas 48 inicializações que variaram entre $22 \mathrm{~h}$ e $1 \mathrm{~h}$ de antecedência. As condições da baixa troposfera nos horários das inicializações são apresentadas a seguir.

\section{Condições sinóticas e de meso escala na baixa troposfera}

A tabela 1 exemplifica as condições sinóticas da troposfera nos horários das inicializações em 2 eventos de nevoeiro. Em geral, as imagens de satélite mostraram em 33 inicializações o céu limpo (próximo a região: 7 inicializações com Sistema Frontal (SF) ou extremidade de um SF e 1 com vórtice no ar frio); 12 com pouca nebulosidade (próximo a região: 5 com SF ou extremidade de um SF, 1 com vórtice no ar frio e 2 com Completo Convectivo de Mesoescala/CCM); e 3 com nebulosidade convectiva (1 do vórtice no ar frio). Os campos gerados com o NCEP e o CFSR-1 para identificar os sistemas sinóticas e de meso escala que causavam as situações apresentadas pelas imagens de satélite no momento das inicializações mostraram diferenças em 16 casos. Em 7 deles as diferenças foram na superfície e/ou no nível de 1000hPa; em outras 7 as diferenças foram detectadas desde a superfície até $1000 \mathrm{hPa}$; e em uma inicialização foram desde $1000 \mathrm{hPa}$ até $850 \mathrm{hPa}$. As reanálises apresentaram condições de sistemas semelhantes nas restantes inicializações. Em particular, 4 delas mostraram cavado desde a superfície até $850 \mathrm{hPa}$ (em 2 inicializações dos casos ocorridos em 05/07/2008 e 04/08/2009 quando o SF estava sobre a região), e em outras 6 apresentavam crista nesta mesma camada (todas apresentaram céu limpo). Nos restantes inicializações apresentaram cristas e cavados em diferentes níveis.

\section{Perfis vertical de UR}

Considerando a condição de perfis de inicialização do PAFOG com relação ao máximo nível da camada úmida desde a superfície até $400 \mathrm{~m}$ (BOTT et al., 2002), foram encontrados os perfis verticais de radiossonda e do CFSR-2 de diferentes tipos (Tabela 2): A: Perfis secos da superfície até o topo da troposfera. B: Perfis úmidos entre a superfície e uma altura inferior a $400 \mathrm{~m}$. C: Perfis com a base da camada úmida localizada numa altura superior a 400 m. D: Perfis úmidos entre a superfície e uma altura superior a 400 m (Tabela 2). 
Levando em conta a configuração do perfil vertical de UR do PAFOG o CFSR-2 apresentou a maior quantidade de perfis favoráveis a inicialização em relação a radiossonda observada. Isso ocorreu porque estudos climatológicos específicos sobre os níveis de altura que os nevoeiros de radiação atingem na cidade de Porto Alegre não foram desenvolvidos, o que impossibilita ajustar o PAFOG a realidade da região. O CFSR mostrou 13 perfis do tipo A, 25 do $B$ (UR máxima registrada na superfície em 22 perfis), 5 do $C$ e 5 do $D$ (com UR variando de $86 \%$ à 100\% numa altura superior à $400 \mathrm{~m}$ ). Os de sondagem mostraram 13 perfis do tipo B, 2 do $C$ e 10 do $D$ (variando de $82 \%$ à $100 \%$ na altura superior à $400 \mathrm{~m}$ ) (tabela 2).

\section{Dinâmica acima da CL}

A tabela 3 exemplifica a velocidade vertical e o vento geostrófico acima da $\mathrm{CL}$ usados nas inicializações do PAFOG com os dados do CFSR-1 e CFSR-2 (inicialização com perfil vertical de radiossonda e do CFSR-2, respectivamente). Em termos gerais, pelos dados do CFSR-2 a velocidade vertical foi descendente em 27 inicializações e ascendente em 21. O CFSR-1 mostrou 10 inicializações com velocidade vertical descendentes e 15 com ascendente. O vento geostrófico no CFSR-2 variou de $0,9 \mathrm{~m} / \mathrm{s}$ a $24,0 \mathrm{~m} / \mathrm{s}$ e no CFSR1 variou de $1,4 \mathrm{~m} / \mathrm{s}$ a $21,2 \mathrm{~m} / \mathrm{s}$. Ventos geostróficos com magnitudes acima de $5 \mathrm{~m} / \mathrm{s}$ estavam associados com confluência ou defluência do escoamento, que geralmente resultavam da passagem de SF no local ou arredores.

Tabela 1: Condições sinóticas e de meso escala da baixa troposfera mostradas pela a reanálise do NCEP e do CFSR-1 nos horários das inicializações (exemplo de parte da tabela). Campos de (1) PNM, Linhas de escoamento e isotacas nos níveis

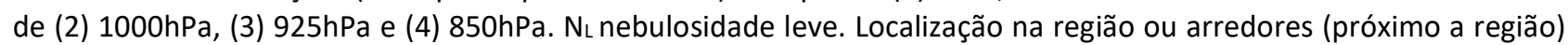
de *SF ou extremidade, @ confluência dos ventos, \& JBN. - fraco. Em negrito o nível para o cálculo do vento geostrófico e a velocidade vertical.

\begin{tabular}{|c|c|c|c|}
\hline Data & NS & NCEP & CFSR \\
\hline 05/07/2008 & $\begin{array}{l}\text { 15h: } \mathrm{N}_{\mathrm{L}}^{*} \\
\text { 09h: } \mathrm{N}_{\mathrm{L}} \\
\text { 03h: } \mathrm{N}_{\mathrm{L}}\end{array}$ & $\begin{array}{l}\text { 15h: (1) C- (2) C@ (3) C (4) C- } \\
\text { 09h: (1) C (2) C (3) C- (4) C } \\
\text { 03h: (1) Cr (2) Cr@ (3) Cr (4) C }\end{array}$ & $\begin{array}{l}\text { 15h: (1) C (2) Cr (3) C@ (4) C- } \\
\text { 09h: (1) C (2) Cr (3) Cr@ (4) C } \\
\text { 03h: (1) Cr (2) Cr (3) Cr (4) C }\end{array}$ \\
\hline 04/08/2009 & $\begin{array}{l}\text { 18h: } \mathrm{N}_{\mathrm{L}}^{*} \\
\text { 12h: } \mathrm{N}_{\mathrm{L}}^{*} \\
06 \mathrm{~h}: \mathrm{N}_{\mathrm{L}}\end{array}$ & $\begin{array}{l}\text { 18h: (1) C (2) C (3) C@ (4) C\& } \\
\text { 12h: (1) C (2) C (3) C@ (4) C\& } \\
\text { 06h: (1) Cr (2)Cr@ (3) Cr@ (4) Cr@ }\end{array}$ & $\begin{array}{l}\text { 18h: (1) C (2) C (3) C@ (4) C\& } \\
\text { 12h: (1) Cr (2) C (3) C@ (4) C\& } \\
\text { 06h: (1) Cr (2) C@ (3) Cr@ (4) Cr@ }\end{array}$ \\
\hline
\end{tabular}

Tabela 2: Condições de UR da baixa troposfera com os perfis de radiossondagem (RADIOSSONDA) e previsão do CFSR (CFSR-2) nos horários das inicializações do modelo PAFOG de todos os nevoeiros de radiação (exemplo de parte da tabela). Valores a seguir à letra B mostram a UR máxima na camada úmida, $\mathrm{C}$ a altura da base da camada úmida e de $\mathrm{D}$ o valor de UR máxima na altura superior à $400 \mathrm{~m}$. *maior valor de UR observada na superfície; xxx: radiossonda indisponível.

\begin{tabular}{|c|c|c|c|c|c|}
\hline Data & CFSR-2 & RADIOSSONDA & Data & CFSR-2 & RADIOSSONDA \\
\hline $18 / 04 / 2008$ & $\begin{array}{l}\text { 21h: D - 87\% } \\
\text { 15h: C - 1067m } \\
\text { 09h: B - 97\%* } \\
\text { 03h: B - 100\%* }\end{array}$ & $\begin{array}{l}\text { 21h: D - 82\% } \\
\text { 09h: C - 664m }\end{array}$ & 03/03/2009 & $\begin{array}{l}\text { 19h: C - 2025m } \\
\text { 13h: B - 94\%* } \\
\text { 07h: B - 96\%* } \\
\text { 01h: B - 100\%* }\end{array}$ & $\begin{array}{l}\text { 19h: D - 86\% } \\
\text { 07h: xxx }\end{array}$ \\
\hline
\end{tabular}

Tabela 3: Condições dinâmicas da baixa troposfera nos horários das inicializações do modelo PAFOG com os dados reanálise (CFSR-1) e previsão (CFSR-2) do modelo CFSR em todos os nevoeiros de radiação (exemplo de parte da tabela). Ant. mostra a hora de antecedência das previsões, $\mathrm{CL}$ a altura da camada limite, $\mathrm{Vg}$ o vento geostrófico e $\mathrm{Vv}$ a velocidade vertical.

\begin{tabular}{|l|l|l|l|l|l|l|l|}
\hline Data & Características & \multicolumn{2}{l|}{ CFSR-2 } & \multicolumn{2}{l|}{ CFSR-1 } \\
\hline \multirow{5}{*}{$05 / 07 / 2008$} & Ant. (h) & $\mathbf{1 5}$ & $\mathbf{0 9}$ & $\mathbf{0 3}$ & - & $\mathbf{1 5}$ & $\mathbf{0 3}$ \\
\cline { 2 - 8 } & $\mathrm{CL}(\mathrm{m})$ & 89 & 680 & 206 & - & 89 & 206 \\
\cline { 2 - 8 } & $\mathrm{Vg}(\mathrm{m} / \mathrm{s})$ & 4.9 & 3.4 & 8.9 & - & 3.6 & 7.3 \\
\cline { 2 - 8 } & $\mathrm{Vv}(\mathrm{m} / \mathrm{s})$ & 1.053 & 0.656 & -0.584 & - & 1.750 & 0.162 \\
\hline
\end{tabular}




\begin{tabular}{|c|c|c|c|c|c|c|c|}
\hline \multirow{4}{*}{ 04/08/2009 } & Ant. (h) & 18 & 12 & 06 & - & 18 & 06 \\
\hline & $\mathrm{CL}(\mathrm{m})$ & 815 & 704 & 144 & - & 815 & 144 \\
\hline & $\operatorname{Vg}(\mathrm{m} / \mathrm{s})$ & 24.0 & 10.9 & 6.7 & - & 21.2 & 5.1 \\
\hline & $\mathrm{Vv}(\mathrm{m} / \mathrm{s})$ & 7.209 & 4.269 & 0.649 & - & 5.369 & 1.455 \\
\hline
\end{tabular}

\section{RESULTADOS E DISCUSSÃO}

\section{Resultado das simulações dos nevoeiros de radiação}

\section{O problema da extrapolação do ponto de orvalho do nível de $\mathbf{2 m}$}

O valor da temperatura do ar em $2 \mathrm{~m}$ de altura foi obtido da extrapolação do valor no nível de superfície da sondagem. Estas extrapolações não causaram problemas nos resultados das simulações. Nos perfis do CFSR-2 o ponto de orvalho em superfície foi obtido a partir do valor desta variável a $2 \mathrm{~m}$ de altura. Como foi mostrado na primeira parte do estudo, os altos valores de UR em baixos níveis durante a noite não foram bem representados pelo modelo CFSR (CFSR-1 e 2). Por isso, nas simulações inicializadas nos horários das 1800UTC nos dias anteriores e das 0600UTC nos dias dos eventos os valores de UR afetaram as simulações.

Maior aquecimento deixa a baixa troposfera mais seca (UR mais dispersa devido à expansão da camada limite) e os erros na extrapolação da UR são mais prováveis. No horário das 1800UTC (nos dias anteriores aos eventos) a maioria dos perfis inicializados do CFSR-2 apresentaram atmosfera seca em baixos ou em todos os níveis da troposfera ( 3 perfis do tipo $C$ e 8 do tipo A), mostrando que neste horário existe maior possibilidade de erros na extrapolação da UR. Os erros foram mais significativos nas inicializações feitas na primavera e no outono, a grande maioria das feitas no inverno (e a única no verão) simularam satisfatoriamente neste horário, embora com valores subestimados de visibilidade.

Às 0600UTC (nos dias dos eventos) a extrapolação da UR influenciou na simulação devido ao pouco tempo de integração do modelo. As simulações afetadas variaram entre $2 \mathrm{~h}$ ( 1 caso) e $1 \mathrm{~h}$ ( 3 casos) de antecedência ao evento (Tabela 4). Em horários próximos ao evento as inicializações devem ser as mais precisas possíveis, por exemplo, é pouco provável ter uma atmosfera com $60 \%$ ou $70 \%$ de UR e passados 1 ou 2 horas se formar nevoeiro de radiação (UR de 100\%), só nos nevoeiros frontais isso pode ocorrer. Por isso, as simulações com $1 \mathrm{~h}$ e $2 \mathrm{~h}$ de antecedência não estão simulando visibilidades dos nevoeiros. Entretanto, a partir de $3 \mathrm{~h}$ de antecedência o PAFOG está simulando visibilidade de nevoeiro porque está dando mais tempo do modelo simular (integrar) as condições para umedecimento.

\section{Resultados das simulações do PAFOG de nevoeiro de radiação}

Os resultados das simulações do PAFOG nos 13 casos de nevoeiros de radiação estão apresentados na tabela 4. Em geral, os resultados foram satisfatórios em todos os eventos, tanto inicializados com dados do CFSR-2 como com de radiossonda, considerando o acerto do nevoeiro em pelo menos uma das simulações de cada caso. A seguir descreve-se detalhadamente os resultados das simulações quando inicializado o PAFOG com dados do CFSR-2 e de radiossondagem do aeroporto. 


\section{Inicialização com os dados do CFSR-2}

As simulações inicializadas com dados do CFSR-2, considerando o perfil vertical de UR, o PAFOG simulou visibilidade de nevoeiro com todos os tipos de perfis. Com perfis do tipo A, B e C acertaram em 9,21 e 3 casos e erraram em 5, 4 e 1, respectivamente. As simulações inicializadas com perfil do tipo D, ou seja, que mostraram uma variação de UR máxima de $86 \%$ a 94\% em uma altura superior a 400 m, o modelo acertou a visibilidade dos nevoeiros em 3 casos. As 2 inicializações, quando a UR máxima variou de 99\% à 100\% neste tipo do perfil, as simulações foram interrompidos. As simulações foram interrompidas porque os dados utilizados nas inicializações não aprovaram nas condições exigidas no modelo (BOTT et al., 2002) (exemplo de 2 casos nas tabelas 1,2 e 3 ).

As interrupções das simulações ocorreram: 1) antes do nevoeiro em 2 casos (18h e 12h de antecedência do dia 04/08/2008), 2) no momento de ocorrência do nevoeiro em 2 casos (20h de antecedência do dia 17/05/2008 e 15h de antecedência do dia 05/07/2008). Essas interrupções foram devido a influência de SF na região (tabela 2 e 4). Em geral, para as inicializações com perfis do CFSR-2 as melhores simulações foram as inicializadas às 1200UTC do dia anterior aos eventos e às 0000UTC do dia dos eventos, ambos com 38,5\% de eficiência; seguido da inicializada às 1800 UTC com 15,3\% e às 0600 UTC do dia do evento $\operatorname{com} 7,7 \%$.

\section{Inicialização com os dados de radiossondagem}

Quando inicializado com os dados de sondagem, o PAFOG acertou a visibilidade dos nevoeiros em 12 simulações com perfis do tipo B. A única simulação que não acertou com este tipo de perfil foi devido aos fortes valores de vento geostrófico $(13,0 \mathrm{~m} / \mathrm{s})$ causados por confluência dos ventos pela proximidade de um SF (20h de antecedência do dia 17/05/2008). Com os perfis do tipo C o modelo simulou acertadamente em 1 inicialização e errou em outra, apesar de ter apresentado condições favoráveis ao uso do modelo (9h de antecedência do dia 18/04/2008). O PAFOG simulou acertadamente em 9 inicializações com os perfis do tipo D. Entre estes casos, em 2 simulações apenas acertou entre as 2 e as 4 primeiras horas do nevoeiro, e em seguida interrompeu a integração. É importante destacar que as simulações interrompidas apresentaram UR máxima de $99 \%$ a $100 \%$ na camada superior a 400 m, enquanto que nas não interrompidas os valores de UR foram de $82 \%$ a $96 \%$.

A única simulação com perfil do tipo D com 18 h de antecedência do dia 04/08/2009, não acertou a visibilidade do nevoeiro, todavia a UR (88\%) foi favorável a simulação correta. Neste caso o vento geostrófico foi de $21,0 \mathrm{~m} / \mathrm{s}$ e foi causado pela presença de uma periferia frontal na região (tabelas $1,2,3$ e 4 ). Esta intensidade do vento geostrófico foi a maior observado de todos os casos.

Nas simulações que foram interrompidas, os dados utilizados nas inicializações não foram favoráveis a utilização do PAFOG de acordo as condições exigidas no modelo (BOTT et al., 2002). Com os perfis de sondagens, 2 simulações interromperam-se antes do horário de registro dos nevoeiros (20 h de antecedência do dia 17/05/2008 e 18 h de antecedência do dia 04/08/2009) e 5 simulações se interromperam depois do 
PAFOG acertar as visibilidades das primeiras horas dos nevoeiros (08h de antecedência do dia 20/04/2008,

15h e 03h de antecedência do dia 05/07/2008, 07h de antecedência do dia 19/06/2009 e 17h de antecedência do dia 20/06/2009).

Tabela 4: Resultados do PAFOG nas simulações de visibilidade em eventos de nevoeiro de radiação, inicializadas com perfis de previsão do CFSR (CFSR-2) e radiossonda observada (RADIOSSONDA). E: visibilidade mínima (m), F: duração (h), em negrito as melhores previsões, *previsões com simulação interrompidas, - simulações que não acertaram a visibilidade dos nevoeiros.

\begin{tabular}{|c|c|c|c|c|c|c|}
\hline \multirow[t]{2}{*}{ Data } & \multicolumn{2}{|c|}{ Observado } & \multicolumn{2}{|l|}{ CFSR-2 } & \multicolumn{2}{|c|}{ RADIOSSONDA } \\
\hline & $\mathbf{E}$ & $\mathbf{F}$ & $\mathrm{E}$ & $\mathbf{F}$ & $\mathrm{E}$ & $\mathbf{F}$ \\
\hline $18 / 04 / 2008$ & 500 & 2,25 & $\begin{array}{l}\text { 21h: } 738 \\
\text { 15h: - } \\
\text { 09h: } 403 \\
\text { 03h: } 812\end{array}$ & $\begin{array}{l}\text { 21h: 6,0 } \\
\text { 15h: - } \\
\text { 09h: 8,0 } \\
\text { 03h: } 1,0\end{array}$ & $\begin{array}{l}\text { 21h: } 61 \\
\text { 09h: - }\end{array}$ & $\begin{array}{l}\text { 21h: } 11,0 \\
09 h:-\end{array}$ \\
\hline $20 / 04 / 2008$ & 200 & 4,75 & $\begin{array}{l}\text { 20h: } 68 \\
\text { 14h: - } \\
\text { 08h: } 413 \\
\text { 02h: } 612\end{array}$ & $\begin{array}{l}\text { 20h: } 8,0 \\
\text { 14h: - } \\
08 \mathrm{~h}: 7,0 \\
02 \mathrm{~h}: 4,0\end{array}$ & $\begin{array}{l}\text { 20h: } 43 \\
\text { 08h: } 57^{*}\end{array}$ & $\begin{array}{l}\text { 20h: } 13,0 \\
\text { 08h: } 11,0\end{array}$ \\
\hline $17 / 05 / 2008$ & 300 & 5,00 & $\begin{array}{l}\text { 20h: 49* } \\
\text { 14h: - } \\
\text { 08h: } 73 \\
\text { 02h: } 738\end{array}$ & $\begin{array}{l}\text { 20h: } 12,0 \\
\text { 14h: }- \\
08 \mathrm{~h}: 10,0 \\
02 \mathrm{~h}: 1,0\end{array}$ & $\begin{array}{l}\text { 20h: }{ }^{*} \\
08 h: 493\end{array}$ & $\begin{array}{l}\text { 20h: } * \\
\text { 08h: 7,0 }\end{array}$ \\
\hline 05/07/2008 & 50 & 11,42 & $\begin{array}{l}\text { 15h: 58* } \\
\text { 09h: } 738 \\
\text { 03h: } 67\end{array}$ & $\begin{array}{l}\text { 15h: } 13,0 \\
09 h: 8,0 \\
03 h: 11,0\end{array}$ & $\begin{array}{l}\text { 15h: } 160^{*} \\
03 \mathrm{~h}: 100^{*}\end{array}$ & $\begin{array}{l}\text { 15h: } 8,0 \\
03 h: 1,0\end{array}$ \\
\hline $15 / 07 / 2008$ & 400 & 4,55 & $\begin{array}{l}\text { 19h: } 41 \\
\text { 13h: } 738 \\
\text { 07h: } 115 \\
\text { 01h: - }\end{array}$ & $\begin{array}{l}\text { 19h: 6,0 } \\
\text { 13h: 3,0 } \\
\text { 07h: 9,0 } \\
\text { 01h: - }\end{array}$ & $\begin{array}{l}\text { 19h: } 41 \\
\text { 07h: } 61\end{array}$ & $\begin{array}{l}\text { 19h: } 14,0 \\
07 h: 12,0\end{array}$ \\
\hline $26 / 08 / 2008$ & 300 & 2,50 & $\begin{array}{l}\text { 21h: } 85 \\
\text { 15h: } 738 \\
\text { 09h: } 46 \\
\text { 03h: } 836\end{array}$ & $\begin{array}{l}\text { 21h: } 11,0 \\
\text { 15h: } 6,0 \\
\text { 09h: } 13,0 \\
\text { 03h: } 1,0\end{array}$ & $\begin{array}{l}\text { 21h: } 42 \\
\text { 09h: } 738\end{array}$ & $\begin{array}{l}\text { 21h: } 14,0 \\
\text { 09h: } 4,0\end{array}$ \\
\hline $27 / 08 / 2008$ & 300 & 1,58 & $\begin{array}{l}\text { 22h: } 995 \\
\text { 16h: } 738 \\
\text { 10h: } 55 \\
\text { 04h: } 738\end{array}$ & $\begin{array}{l}22 \mathrm{~h}: 1,0 \\
\text { 16h: } 6,0 \\
\text { 10h: } 12,0 \\
04 h: 2,0\end{array}$ & $\begin{array}{l}\text { 22h: } 111 \\
\text { 10h: } 86\end{array}$ & $\begin{array}{l}22 h: 9,0 \\
10 h: 10,0\end{array}$ \\
\hline 03/03/2009 & 150 & 5,25 & $\begin{array}{l}\text { 19h: } 749 \\
\text { 13h: } 121 \\
\text { 07h: } 738 \\
\text { 01h: - }\end{array}$ & $\begin{array}{l}\text { 19h: } 5,0 \\
\text { 13h: } 12,0 \\
07 h: 5,0 \\
\text { 01h: - }\end{array}$ & $\begin{array}{l}\text { 19h: } 738 \\
\text { 07h: xxx }\end{array}$ & $\begin{array}{l}\text { 19h: } 6,0 \\
07 h: x x x\end{array}$ \\
\hline 03/05/2009 & 300 & 5,58 & $\begin{array}{l}\text { 18h: } 621 \\
\text { 12h: - } \\
\text { 06h: } 738\end{array}$ & $\begin{array}{l}\text { 18h: } 8,0 \\
\text { 12h: - } \\
\text { 06h: } 6,0\end{array}$ & $\begin{array}{l}\text { 18h: } 574 \\
\text { 06h: } 67\end{array}$ & $\begin{array}{l}\text { 18h: } 8,0 \\
06 h: 10,0\end{array}$ \\
\hline $10 / 05 / 2009$ & 300 & 4,67 & $\begin{array}{l}\text { 20h: } 901 \\
\text { 14h: - } \\
\text { 08h: } 752 \\
\text { 02h: - }\end{array}$ & $\begin{array}{l}\text { 20h: } 2,0 \\
\text { 14h: - } \\
\text { 08h: 4,0 } \\
\text { 02h: - }\end{array}$ & $\begin{array}{l}\text { 20h: } 52 \\
\text { 08h: } 100\end{array}$ & $\begin{array}{l}\text { 20h: } 13,0 \\
\text { 08h: } 10,0\end{array}$ \\
\hline $19 / 06 / 2009$ & 500 & 5,01 & $\begin{array}{l}\text { 19h: } 59 \\
\text { 13h: } 746 \\
\text { 07h: } 64 \\
\text { 01h: - }\end{array}$ & $\begin{array}{l}\text { 19h: } 11,0 \\
\text { 13h: } 4,0 \\
07 \mathrm{~h}: 12,0 \\
01 \mathrm{~h}:-\end{array}$ & $\begin{array}{l}\text { 19h: } 86 \\
\text { 07h: } 73^{*}\end{array}$ & $\begin{array}{l}\text { 19h: } 13,0 \\
07 h: 12,0\end{array}$ \\
\hline 20/06/2009 & 200 & 7,00 & $\begin{array}{l}\text { 17h: } 738 \\
\text { 11h: - } \\
\text { 05h: } 930\end{array}$ & $\begin{array}{l}\text { 17h: } 8,0 \\
\text { 11h: - } \\
05 \mathrm{~h}: 1,0\end{array}$ & $\begin{array}{l}\text { 17h: } 48^{*} \\
\text { 05h: } 738\end{array}$ & $\begin{array}{l}\text { 17h: } 11,0 \\
05 h: 5,0\end{array}$ \\
\hline 04/08/2009 & 150 & 6,33 & $\begin{array}{l}\text { 18h: * } \\
\text { 12h: * } \\
\text { 06h: } 101\end{array}$ & $\begin{array}{l}\text { 18h: * } \\
\text { 12h: * } \\
\text { 06h: 7,0 }\end{array}$ & $\begin{array}{l}\text { 18h: * } \\
\text { 06h: } 482\end{array}$ & $\begin{array}{l}\text { 18h: * } \\
06 h: 6,0\end{array}$ \\
\hline
\end{tabular}

Simulação do nevoeiro de radiação com maior duração

\section{Condições de inicialização}




\section{Condições sinóticas na baixa troposfera}

As interrupções aconteceram por conta da influência de SF na maior parte dos eventos, onde influenciaram nas condições termodinâmicas e dinâmicas da baixa atmosfera nas horas das inicializações. Isto aconteceu quando o vento geostrófico variando de $7,3 \mathrm{~m} / \mathrm{s}$ à $21,4 \mathrm{~m} / \mathrm{s}$ e perfis do tipo $D$ com UR máxima de 99\% a 100\% acima de 400 m. Também aconteceu em 20/06/2009 quando na hora da inicialização ocorreu nevoeiro.

As inicializações com perfis de sondagem ás 1200UTC do dia anterior e ás 0000UTC do dia dos eventos ambas tiveram 50\% de aproveitamento (Tabela 4). Na opinião dos autores, o problema encontrado no resultado da simulação do PAFOG com inicializações de perfis de sondagem foi devido à mistura de fontes de informações necessárias para inicializar o modelo. Ou seja, vento geostrófico e velocidade vertical foram obtidos do CFSR-1 e perfil termodinâmico de sondagem. Com esse resultado, o PAFOG simulou uma visibilidade mínima de 1020 metros, muito próximo a visibilidade de nevoeiro que é menor a 1000 metros. Isto aconteceu em uma única inicialização que apresentou condições favoráveis ao uso do modelo (9h de antecedência do dia 18/04/2008).

As imagens de satélite no evento de maior duração (05/07/2008) mostram fraca nebulosidade sobre Porto Alegre (PA) e a extremidade de um SF próximo a região no horário da inicialização com $15 \mathrm{~h}$ de antecedência ao nevoeiro (dia 04 as 1200UTC, figura 2 a). A extremidade do SF foi confirmada no campo de advecção de temperatura potencial equivalente (figura $2 \mathrm{~d}$ ). A nebulosidade associada com a extremidade do SF esteve localizada distante de PA nas 2 próximas inicializações (com 09 e 03 h de antecedência), enquanto que sobre PA foi observado nuvens de textura filamentosa (figura $2 \mathrm{~b}$ e c).
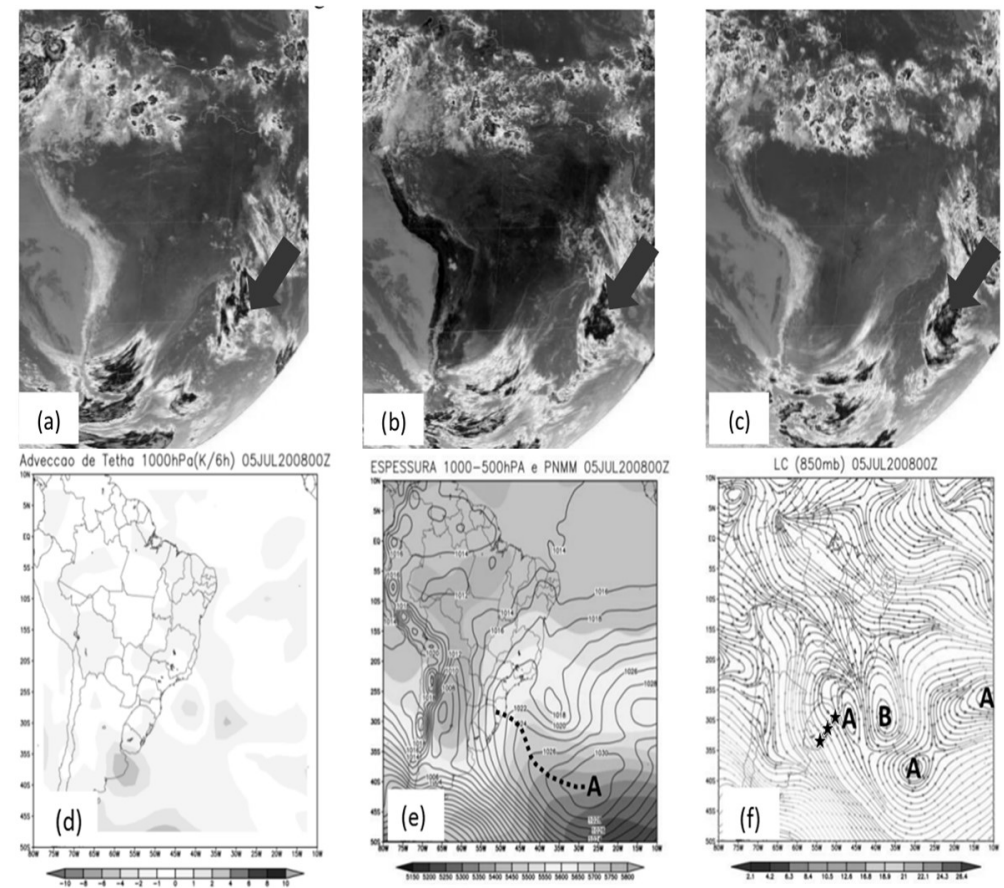

Figura 2: Imagem de satélite no canal IR com 15 (a), 09 (b) e 03 (c) horas de antecedência ao evento de nevoeiro, campos de advecção de temperatura potencial equivalente em $1000 \mathrm{hPa}(\mathrm{d})$, espessura da camada entre 1000-500hPa (e) e linhas de escoamento e magnitude do vento ( $\mathrm{f}$ ) com $03 \mathrm{~h}$ de antecedência ao nevoeiro. Setas o sistema frontal, A o anticiclone, B o ciclone, linha tracejada a crista e linha estrela o cavado. 
No campo de pressão ao nível do mar os modelos NCEP e CFSR-1 mostraram um cavado sobre PA nas 2 primeiras inicializações (15 h e 09 h de antecedência), enquanto que na inicialização com 3 h de antecedência PA estava sob influência de uma crista (figura 2 e). Em 850hPa o campo de vento mostrou um cavado sobre PA nas 3 inicializações (figura 2 f).

\section{Perfis de UR e dinâmica acima da CL}

Todos os perfis de UR do CFSR-2 apresentaram condições favoráveis para o uso do PAFOG nos horários das inicializações. A camada úmida esteve abaixo de $400 \mathrm{~m}$ em duas inicializações (15 h e 03 h de antecedência, da superfície até 390 m com UR máxima de 93\% e até 168 m com UR máxima de 99\%, respetivamente). Com $09 \mathrm{~h}$ de antecedência a troposfera estava seca em baixos níveis, a camada úmida localizou-se na altura acima de 400 m (602 m com UR de 81\% e de 1292 m à 1534 m com UR máxima de 84\%), figura 3 a-c. O vento geostrófico e a velocidade vertical acima da camada limite foram de 4,9 m/s com $1,053 \mathrm{~m} / \mathrm{s}, 3,4 \mathrm{~m} / \mathrm{s}$ com $0.656 \mathrm{~m} / \mathrm{s}$ e $8.9 \mathrm{~m} / \mathrm{s}$ com $-0.584 \mathrm{~m} / \mathrm{s}$ nas inicializações de $15 \mathrm{~h}, 09 \mathrm{~h}$ e $03 \mathrm{~h}$ de antecedência, respectivamente (Tabela 3).

Os perfis de sondagens observadas inicializados no PAFOG mostraram condições desfavoráveis para o uso do modelo. A altura da camada úmida desde a superfície excedeu os $400 \mathrm{~m}$ (valor parametrizado no PAFOG). Desde a superfície, as camadas atingiram a altura de 835 m e 413 m nas inicializações com 15 h e 03 h de antecedência, respectivamente, com valores de UR nos níveis acima de 400 m de 99\% e 100\%, respectivamente (figura $3 \mathrm{~d}$-e). A dinâmica acima da CL mostrou vento geostrófico e velocidade vertical de $3,6 \mathrm{~m} / \mathrm{s}$ com $1,750 \mathrm{~m} / \mathrm{s}$ e 7,3 m/s com 0,162 m/s nas inicializações com $15 \mathrm{~h}$ e $09 \mathrm{~h}$ de antecedência, respectivamente (tabela 3 ).
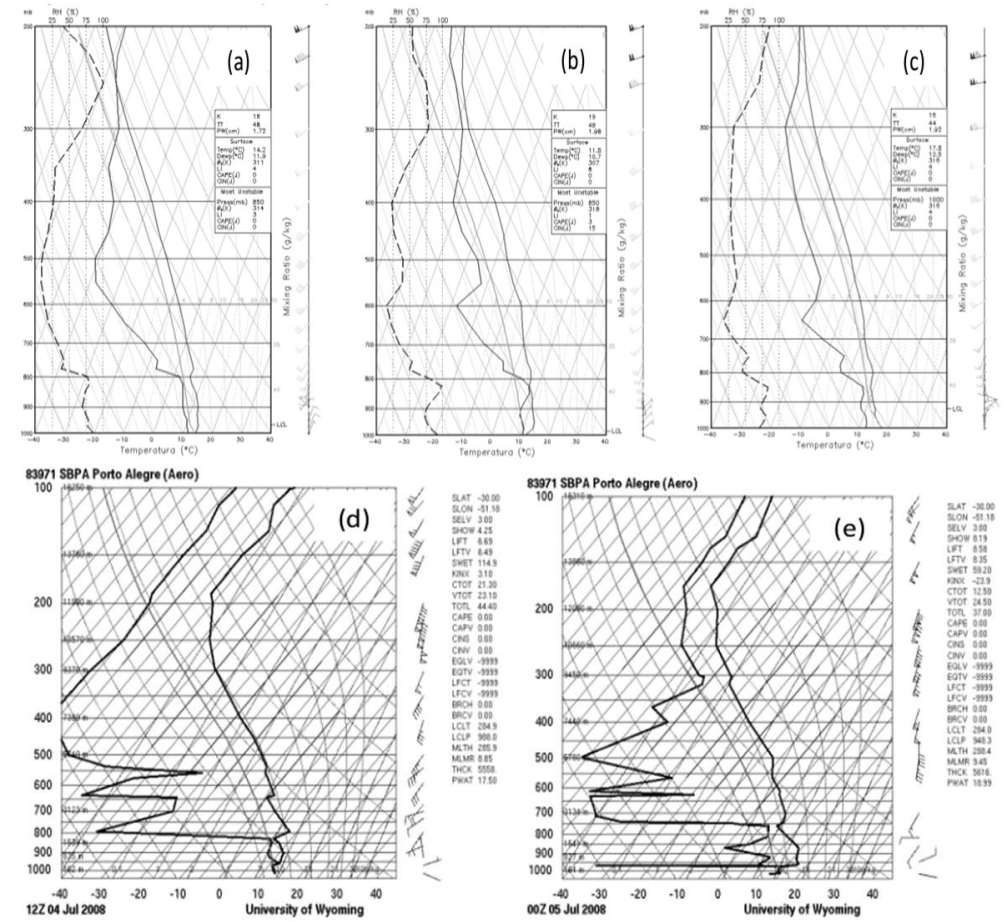

Figura 3 Perfis verticais de temperatura e umidade usados para inicializações do PAFOG, do CFSR-2 para as previsões de $15 \mathrm{~h}$ (b), 09h (c) e 03h (c) de antecedência, de sondagem observada de 15h (d) e 03h (e) horas de antecedência. 


\section{Resultado das simulações}

\section{Inicialização com CFSR-2}

Os resultados das simulações com os perfis do CFSR são mostrados na figura 4. A simulação foi satisfatória, o modelo acertou visibilidade de nevoeiro com todas as inicializações. As visibilidades mínimas previstas foram de $57 \mathrm{~m}, 738 \mathrm{~m}$ e $73 \mathrm{~m}$ com duração de 13.0, 8.0 e 11.0 horas nas simulações com $15 \mathrm{~h}, 09 \mathrm{~h}$ e $3 \mathrm{~h}$ de antecedência, respectivamente. A visibilidade mínima observada foi de $50 \mathrm{~m}$ e o nevoeiro durou de 11,42 horas. A simulação com 09 h de antecedência subestimou o nevoeiro por conta do erro da extrapolação do ponto de orvalho (figura 4, linha azul).

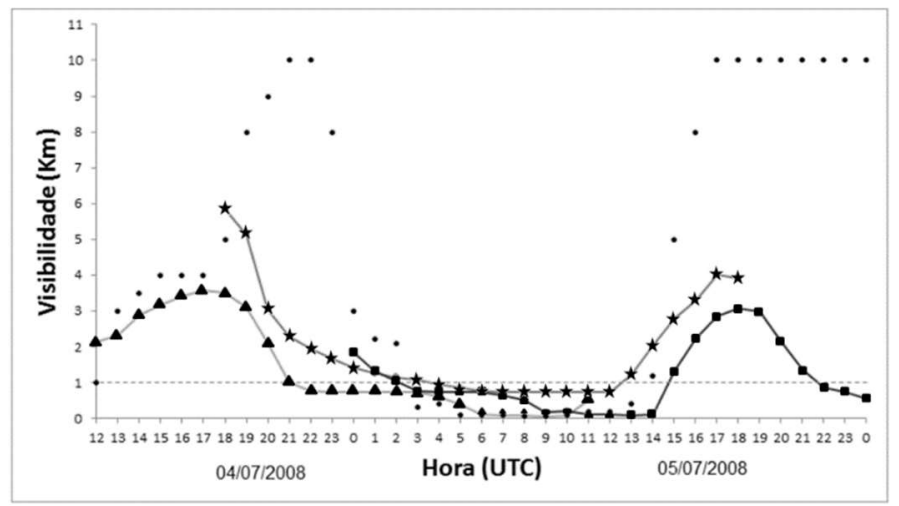

Figura 4: Simulações de visibilidade horizontal do PAFOG com inicializações de perfis do CFSR-2. Pontos preto a visibilidade observada, linhas a visibilidade simulada pelo PAFOG com 15 (marcador triângulo), 09 (marcador estrela) e 03 (marcador quadrado) horas de antecedência ao nevoeiro.

\section{Inicialização com perfis de radiossonda}

O PAFOG simulou as primeiras horas do nevoeiro e em seguida interrompeu-se quando inicializado com perfis de radiossonda observado (figura 5). Com $15 \mathrm{~h}$ de antecedência o modelo acertou as 4 primeiras horas do nevoeiro, simulou valor de visibilidade mínima de 160 metros (Figura 5 a, linha laranja) e com 03 h acertou as 2 primeiras horas simulando visibilidade mínima de 100 metros (Figura 5 a, linha vermelha). Este evento de nevoeiro para além de apresentar a maior duração (tabela 4) também apresentou, no perfil observado de radiossonda, a maior altura de acúmulo de UR em baixos níveis (309 $\mathrm{m}$ de profundidade). Entretanto, os perfis inicializados (Figura $3 \mathrm{~d}$-e) também apresentaram camada úmida profunda, valores que ultrapassaram os $400 \mathrm{~m}$ configurado como limite no PAFOG.

Baseando-se nos estudos de Fedorova et al. (2008) se configurou o valor de 700 m no parâmetro da profundidade de nevoeiro no PAFOG, no entanto, o teste foi feito apenas na simulação com $03 \mathrm{~h}$ de antecedência. O teste mostrou uma melhoria na simulação da visibilidade do evento, aumentando a duração para 9 horas e visibilidade mínima de 69 metros (Figura 5 b, linha vermelha). Este teste mostrou a necessidade de configurar o PAFOG com as condições termodinâmicas dos nevoeiros de radiação que ocorrem sobre PA, pois essa região é de maior frequência desse fenômeno no Brasil (TUBELIS et al., 1983). 


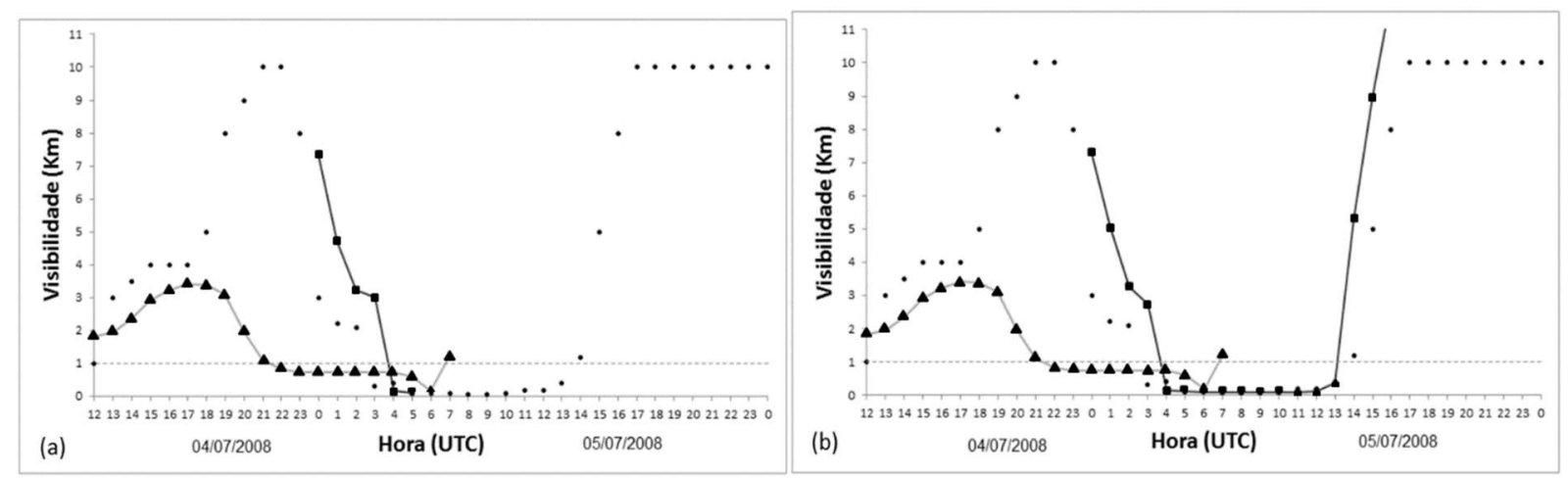

Figura 5: Simulações de visibilidade horizontal do PAFOG com inicializações de perfis observados de radiossonda. Configuração do parâmetro altura do nevoeiro de 400 m (a) e 700 m (b). Pontos circular a visibilidade observada, linhas a visibilidade simulada pelo PAFOG com 15 (marcador triângulo) e 03 (marcador quadrado) horas de antecedência ao nevoeiro.

\section{Exemplo do nevoeiro de radiação com simulações influenciadas por periferias frontais}

O nevoeiro de radiação mostrado como exemplo ocorreu no dia 04 de Agosto de 2009. A figura 6 (a - f) ilustra as condições sinópticas nos horários das inicializações e também o resultado das simulações do PAFOG. Nas inicializações com $18 \mathrm{~h}$ e $12 \mathrm{~h}$ de antecedência as imagens de satélite e linhas de corrente mostram um SF influenciando PA. Os perfis de UR do CFSR-2 mostraram camada úmida desde a superfície até a altura de 1740 m com UR máxima de 100\%, e até a altura de 1283 m com UR máxima de 99\%, isso nas inicializações com 18 h e 12 h de antecedência, respectivamente. As simulações correspondentes à essas inicializações foram interrompidas (figura $6 \mathrm{~g}$, linhas laranja e azul).

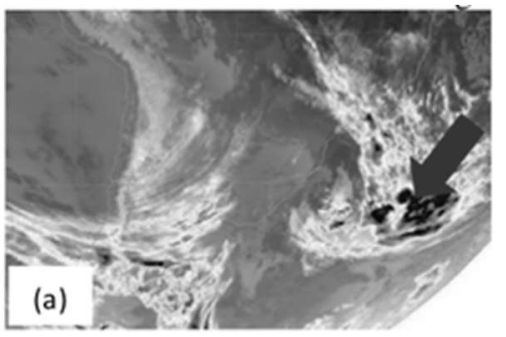

(1)

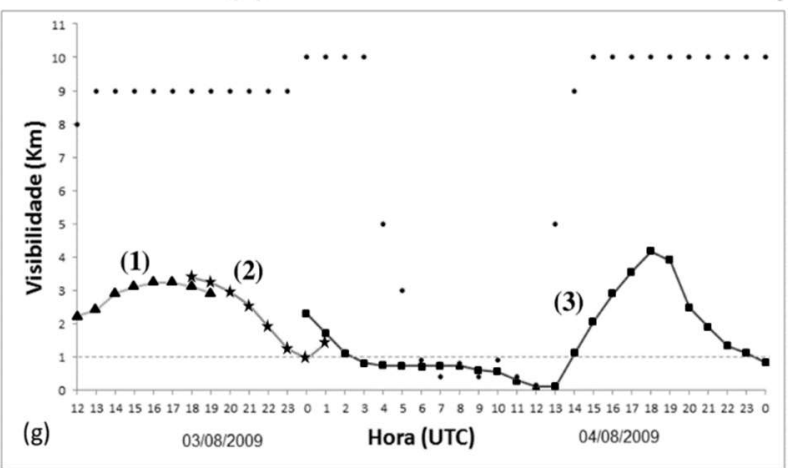

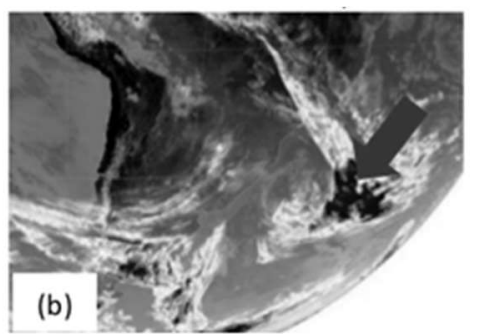

(2)

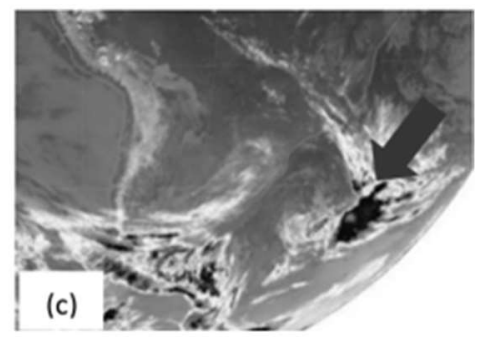

(3)

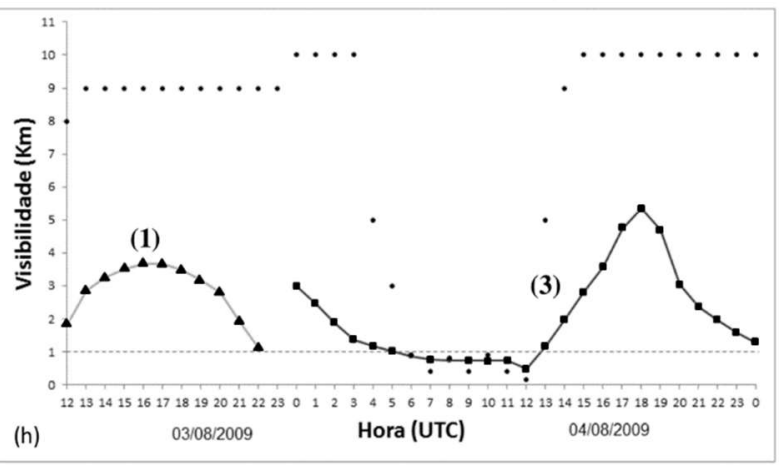

Figura 6: Situação sinótica as 1200UTC (a), 1800UTC (b) do dia 03 e as 0000UTC (c) do dia 04 de Agosto de 2009 (exemplo de parte da figura). Simulações de visibilidade horizontal do PAFOG com inicializações de perfis do CFSR-2

(g) e observados de radiossondagem (h). Linhas a visibilidade simulada pelo PAFOG com 18 (marcador triângulo), 12 (marcador estrela) e 06 (marcador quadrado) horas de antecedência ao nevoeiro, pontos circular a visibilidade observada, setas o sistema frontal.

O mesmo aconteceu na simulação com $18 \mathrm{~h}$ de antecedência (figura $6 \mathrm{~h}$, linha laranja) usando o perfil de radiossonda observado. Os mesmos mostraram camada úmida desde a superfície até $808 \mathrm{~m}$ e UR máxima 
de $99 \%$. Os ventos geostróficos intensos, resultados da atuação do SF, também foram os fatores que influenciaram na interrupção destas simulações (de 24,0 m/s e 10,9 m/s com 18 h e 12 h de antecedência no CFSR-2 e de $21,2 \mathrm{~m} / \mathrm{s}$ com $18 \mathrm{~h}$ de antecedência na sondagem observada), tabela 3.

No horário de inicialização para a simulação de $6 \mathrm{~h}$ de antecedência PA estava sob a influência de um anticiclone da retaguarda do SF (figura 6 c e f). Os perfis inicializados apresentaram condições para o uso do PAFOG (tabela 2) e ventos geostrófico favorável (tabela 3). As simulações acertaram a visibilidade do nevoeiro com valores mínimos de $101 \mathrm{~m}$ e duração de 7,0 h com o perfil do CFSR-2 e de $482 \mathrm{~m}$ e 6,0 h com o perfil de sondagem observada. A estação meteorológica do aeroporto registrou visibilidade mínima de 150 $\mathrm{m}$ e duração de 6,33 h (Figura $6 \mathrm{~g}$ e $\mathrm{h}$ linha vermelha, respectivamente).

\section{CONCLUSÕES}

O PAFOG foi testado para simulação de visibilidade dos 13 casos de nevoeiros de radiação registrados nos horários de radiossondagem, nos anos de 2008 e 2009 no aeroporto Salgado Filho - Porto Alegre/RS. Foram feitas 25 simulações com perfis vertical de radiossonda e 48 com perfis previstos do CFSR (CFSR-2). 0 modelo PAFOG foi capaz de prever as baixas visibilidades dos nevoeiros com prazos de antecedência variando entre $1 \mathrm{~h}$ e $22 \mathrm{~h}$.

As condições físicas da baixa troposfera sobre Porto Alegre, nos horários de inicialização das simulações foram analisadas. Na análise sinótica e de meso escala pela imagem de satélite em 33 inicializações o céu estava limpo, em 12 com pouco nebulosidade e em 3 com nebulosidade convectiva. Os campos gerados com as reanálises do NCEP e do CFSR (CFSR-1) mostraram diferenças nos horários de 16 inicializações: em 7 na superfície; em 7 no nível de 1000hPa; em 1 desde a superfície até 1000hPa; e em 1 desde $1000 \mathrm{hPa}$ até $850 \mathrm{hPa}$. Os perfis de UR inicializados foram classificados da seguinte forma: 1) tipo A: perfis secos da superfície até o topo da troposfera; 2) tipo B: perfis úmidos entre a superfície e uma altura inferior a 400m; 3) tipo C: Perfis com a base da camada úmida localizada numa altura superior a 400m; 4) tipo D: Perfis úmidos entre a superfície e uma altura superior a 400m. Com o CFSR-2 foram inicializados 13, 25, 5 e 5 casos dos tipos A, B, C e D, respectivamente. Com relação aos perfis de sondagem se encontrou 13, 2 e 10 casos dos tipos B, C e D, respectivamente. De acordo a configuração do perfil vertical de umidade no PAFOG, o CFSR-2 em relação a radiossonda apresentou a maior quantidade de perfis favoráveis a utilização do PAFOG. Foi possível observar, na análise da dinâmica acima da $C L$ que ventos geostróficos acima de $5 \mathrm{~m} / \mathrm{s}$ estavam associados geralmente à passagem de SF no local ou arredores. O vento geostrófico no CFSR-2 variou entre $0,9 \mathrm{~m} / \mathrm{s}$ e $24,0 \mathrm{~m} / \mathrm{s}$, enquanto no CFSR-1 variou entre $1,4 \mathrm{~m} / \mathrm{s}$ e $21,2 \mathrm{~m} / \mathrm{s}$.

Em geral, as simulações de visibilidade dos nevoeiros de radiação foram satisfatórias. Em algumas simulações o modelo não acertou os nevoeiros devido a problemas induzidos pela extrapolação do ponto de orvalho, quando inicializado com perfis do CFSR-2. Ocorreu nas simulações inicializadas às 1800UTC do dia anterior aos eventos, onde o máximo aquecimento influenciou na dispersão da UR em baixos níveis. Os erros foram menores no inverno, em relação as outras épocas do ano. As inicializações das 0600UTC no dia dos eventos também foram influenciadas por erro da extrapolação de UR, porém, a influência da imprecisão no 
valor de UR extrapolado foi maior devido ao menor tempo que o modelo teve para reagir. Os erros nessas inicializações (das 0600UTC) foram maiores nas simulações com $2 \mathrm{~h}$ e $1 \mathrm{~h}$ de antecedência em relação a $4 \mathrm{~h}$ e 3h de antecedência aos eventos.

Quando inicializado com perfis do CFSR-2 o PAFOG acertou os nevoeiros em 36 simulações de todos os tipos de perfil vertical (A, B, C e D) e falhou em 12 simulações. Em 10 ocasiões as falhas se deveram aos erros na extrapolação da UR. Nas outras duas simulações, que falharam, os perfis verticais não cumpriramse as condições estabelecidas no modelo: 1) perfil do tipo D com UR máxima de 99\% a 100\% acima da altura de $400 \mathrm{~m}$ e 2) os ventos geostrófico foram elevados $(10,9 \mathrm{~m} / \mathrm{s}$ a $24,0 \mathrm{~m} / \mathrm{s})$ devido a influência de SF.

As simulações inicializadas com perfis de radiossonda, o modelo simulou de forma acertada o nevoeiro em 22 simulações, e não simulou em 3 inicializações. Os erros de simulação em 2 delas foram devido aos ventos geostróficos elevados $(13,0 \mathrm{~m} / \mathrm{s}$ e $21,2 \mathrm{~m} / \mathrm{s}$ nas previsões com $20 \mathrm{~h}$ de antecedência no dia 17/05/2008 e 18h de antecedência no dia 04/08/2009, respectivamente). Nestes dois casos foi influência de periferia frontal.

As melhores simulações, quando o modelo foi inicializado com perfis do CFSR-2, foram as das 1200 UTC do dia anterior ao evento (entre $21 \mathrm{~h}$ e $17 \mathrm{~h}$ de antecedência ao evento) e das 0000UTC do dia do evento (entre 9h e 7h de antecedência). Com inicialização de perfis de radiossonda os dois horários tiveram desempenhos semelhantes. Os resultados mostraram um grande potencial do uso do PAFOG nas previsões de nevoeiro no aeroporto Salgado Filho, mas também mostraram que é necessário mais estudos para adaptar o modelo às condições climatológicas de nevoeiro de radiação desta região, como o exemplo visto, os níveis de altura que os nevoeiros de radiação atingem na cidade de Porto Alegre.

\section{REFERÊNCIAS}

BOTT, A.; SIEVERS, U.; ZDUNKOWSKI, W.. A radiation fog model with a detailed treatment of the interaction between radiative transfer and fog microphysics. Journal of Atmospheric Science, v.47, n.18, p.2153-2166, 1990.

BOTT, A.; TRAUTMANN, T.. PAFOG: A new efficient forecast model of radiation fog and low-level stratiform clouds. Atmospheric Research, v.64, p.191-203, 2002.

FEDOROVA, N.; LEVIT, V.; FEDOROV, D.. Fog and Stratus Formation on the Coast of Brazil. Atmospheric Research, v.87, p.268-278, 2008.

FEDOROVA, N.; LEVIT, V.; SILVA, A. O.; SANTOS, D. M. B.. Low Visibility Formation and Forecasting on the Northern Coast of Brazil. Pure and Applied Geophysics, v.170, n.4, p.689709, 2013.

FEDOROVA, N.; LEVIT, V.; SOUZA, J. L.; SILVA, A. O.; AFONSO, J. M. S.; TEODORO, I.. Fog Events at Maceio Airport on the Northern Coast of Brazil During 2002-2005 and 2007. Pure and Applied Geophysics, v.172, n.10, p.2727-2749, 2015. DOI: http://doi.org.10.1007/s00024-014-1027-0

KALNAY, E.; KANAMITSU, M.; KISTLER, R.; COLLINS, W.; DEAVEN, D.; GANDIN, L.; IREDELL, M.; SAHA, S.; WHITE, G.; WOOLLEN, J.; ZHU, Y.; CHELLIAH, M.; EBISUZAKI, W.;
HIGGINS, W.; JANOWIAK, J.; MO, K. C.; ROPELEWSKI, C.; WANG, J.; LEETMAA, A.; REYNOLDS, R.; JENNE, R.; JOSEPH, D.. The NCEP/NCAR 40-Year Reanalysis project. Bulletin of the American Meteorological Society, v.77, p.437-471, 1996.

MELLOR, G. L.; YAMADA, T.. Development of a turbulence closure model for geophysical fluid problems. Rev. Geophys. Space Phys, v.20, p.851-875, 1982.

PIELKE, R. A.. Mesoscale meterological modeling. Orlando: Academic Press, 1984.

SIEBERT, J.; BOTT, A.; ZDUNKOWSKI, W.. Influence of a vegetation-soil model in the simulation of radiation fog. Beitr. Phys. Atmos, v.65, p.93-106, 1992a.

SIEBERT, J.; SIEVERS, U.; ZDUNKOWSKI, W.. A onedimensional simulation of the interaction between land surface processes and the atmosphere. Boundary: Layer Meteorol, v.59, p.1-34, 1992b.

SMITH, W. H. F.; SANDWELL, D. T.. Global Seafloor Topography from Satellite Altimetry and Ship Depth Soundings. Science, v.277, p.1956-1962, 1997.

TUBELIS, A.; NASCIMENTO, F. J. L.. Meteorologia Descritiva: Fundamentos e Aplicações Brasileiras. São Paulo: Nobel, 
1983.

WILLET, H. C.. Fog and haze, their causes, distribution, and forecasting. Monthly Weather Review, Washington, v.56, p.435-468, 1928.
ZDUNDOWSKI, W. G.; PANHANS, W. G.; WELCH, R. M.; KORB, G. J.. A radiation scheme for circulation and climate models. Beitr. Phys. Atmos, v.55, p.215-238, 1982.

A CBPC - Companhia Brasileira de Produção Científica (CNPJ: 11.221.422/0001-03) detém os direitos materiais desta publicação. Os direitos referem-se à publicação do trabalho em qualquer parte do mundo, incluindo os direitos às renovações, expansões e disseminações da contribuição, bem como outros direitos subsidiários. Todos os trabalhos publicados eletronicamente poderão posteriormente ser publicados em coletâneas impressas sob coordenação da Sustenere Publishing, da Companhia Brasileira de Produção Científica e seus parceiros autorizados. Os (as) autores (as) preservam os direitos autorais, mas não têm permissão para a publicação da contribuição em outro meio, impresso ou digital, em português ou em tradução. 